\title{
Functionality of maize, wheat, teff and cassava starches with stearic acid and xanthan gum
}

\section{Thabelang Gladys Maphalla and Mohammad Naushad Emmambux*}

University of Pretoria, Department of Food Science, Private Bag X20, Hatfield, Pretoria 0028, South Africa

*Corresponding author. Tel: $\quad+27 \quad 12 \quad 420 \quad 2059$; fax: $+27 \quad 12420$ 2839. $\quad$ E-mail address: naushad.emmambux@up.ac.za (M.N.Emmambux).

\begin{abstract}
Consumer concerns to synthetic chemicals have led to strong preference for 'clean' label starches. Lipid and hydrocolloids are food friendly chemicals. This study determines the effects of stearic acid and xanthan gum alone and in combination on the functionality of maize, wheat, teff and cassava starches. An increase in viscosity was observed for all starches with stearic acid and xanthan gum compared to the controls with cassava having the least increase. A further increase in viscosity was observed for the cereal starches with combination of stearic acid and xanthan gum. Stearic acid reduced retrogradation, resulting in soft textured pastes. Combination of stearic acid and xanthan gum reduced the formation of type IIb amylose-lipid complexes, syneresis, and hysteresis in cereal starches compared to stearic acid alone. A combination of stearic acid and xanthan gum produce higher viscosity non-gelling starches and xanthan gum addition increases physical stability to freezing and better structural recovery after shear.
\end{abstract}

Keywords: Starch, viscosity, amylose-lipid complex, flow property, lipid, xanthan gum

\section{Introduction}

Starch contributes to the viscosity, texture, mouth-feel and consistency of food products (Blazek \& Copeland, 2009). Foods made with native starches as an ingredient have low process tolerance for commercial manufacturing (Mason, 2009). Native starches are chemically modified to improve their tolerance to processing conditions (BeMiller, 2011). This is due to low stability to thermal and shearing of native starches and tendency to retrograde (Arocas, Sanz \& Fiszman, 2009). The increase in consumer concerns (Brennan, 
Tan, Kuri \& Tudorica, 2004) has led to a strong preference for 'clean label' starches (Arocas et al., 2009) compared to 'synthetic' chemicals. Lipid and hydrocolloids are food friendly chemicals for 'clean label' starches. The presence of endogenous lipids or the addition of lipids to starch changes their pasting properties with heating at $90^{\circ} \mathrm{C}$ for 120 min (Nelles, Dewar, Bason \& Taylor, 2000; D’Silva, Taylor \& Emmambux, 2011). D’Silva et al. (2011) showed a continuous increase in viscosity for maize and teff starches with added stearic acid during pasting. Biliaderis and Galloway (1989) showed that during annealing, amylose can interact with lipids resulting in the formation of amylose-lipid complexes. Wokadala, Ray and Emmambux (2012) showed the occurrence of amylose-lipid complexes during pasting using Differential Scanning Calorimetry (DSC) (endothermic peaks at $\mathrm{T}_{\mathrm{p}} \approx 100^{\circ}$ and $\approx 110^{\circ} \mathrm{C}$ ) and Wide Angle X-ray Scattering (WAXS) $\left(2 \theta=7.5^{\circ}, 12.7^{\circ}\right.$ and $\left.19.9^{\circ}\right)$. Thus amylose-lipid complexes are shown to be responsible for the increase in viscosity during pasting (Wokadala et al., 2012). It has also been shown that the addition of lipids can reduce retrogradation of amylose during cooling and storage (Blazek \& Copeland, 2009; D’Silva et al., 2011).

Studies have shown that the addition of hydrocolloids such as xanthan gum to starch can also have an effect on the pasting properties. The addition of xanthan gum to rice starch has been observed to increase peak, breakdown, final and setback viscosities during pasting (Viturawong, Achayuthakan \& Suphantharika, 2008). Weber, Clerici, Collares-Queiroz and Chang (2009) observed that addition of xanthan gum to maize starch showed an increased paste viscosity. An increase in peak viscosity has also been observed for normal maize, wheat and cassava starch with xanthan gum during pasting (Bahnassey \& Breene, 1994). The increase in viscosity has been attributed to the interaction between gums and amylose (Shi \& BeMiller, 2002). Addition of xanthan gum can improve the stability of the maize starch by amylose-gum and amylopectin-gum interaction between the polymer chains (He, Zhang, Hong $\& \mathrm{Gu}, 2015)$. In addition Hong, Wu, Liu and Gu (2015) suggested that xanthan gum is more likely to interact with amylose molecules as the increase in amylose content of maize starch showed more effects in terms of pasting properties. Interaction between xanthan gum and starch molecules was suggested to be hydrogen bonding (Weber et al., 2009). 
Many research has shown the effects of stearic acid and xanthan gum alone but the effects of the combination of stearic acid and xanthan gum on the functionality of starch has not been reported. In this research the objective was to determine the effects of stearic acid and xanthan gum alone and in combination on the pasting, textural properties and freeze-thaw stability of maize, wheat, teff and cassava starches.

\section{Materials and methods}

\subsection{Materials}

Commercial white maize starch $\left(\right.$ Amyral $^{\circledR}$ ) was obtained from Tongaat hullet ${ }^{\circledR}$ (Edenvale, South Africa). Teff starch was extracted from white teff variety obtained from Pannar® (Pty) Ltd (Kroonstad, South Africa). Wheat starch was obtained from Latenstein Zetmeel B.V (Rotterdam, Netherlands). Low moisture tapioca was obtained from Ingredion (Pty) Ltd (Meyersdal, South Africa). Stearic Acid (approx. 97\% GC grade) was obtained from Merck (Pty) Ltd (Modderfontein, South Africa). Xanthan gum was obtained from Chemimpo (Pty) Ltd (Randburg, South Africa). The moisture content of maize, wheat, teff and cassava starches were repectively 9.0, 12.0, 1.0 and 7.5\%. The crude fat for maize, wheat and cassava starches were about $0.2 \%$ respectively and for teff starch it was about $0.1 \%$ on dry basis $(\mathrm{db})$. The protein content of maize, wheat, teff and cassava starch were respectively $0.6,0.6,1.3$ and $0.3 \% \mathrm{db}(\mathrm{N} \times 6.25)$. The amylose content of maize, wheat, teff and cassava starches as

determined according to the method by megazyme® (Bray, Ireland) amylose/amylopectin assay kits was 25.2, 34.9, 22.4 and 15.2\%.

\subsection{Methods}

\subsubsection{Starch pasting using Rapid visco analyser}

A rapid visco analyzer unit, RVA, Model 3D, Newport Scientific (Pty) Ltd (Warriewood, Australia) was used for pasting and to record viscosity. Stearic acid was incorporated into the starch according to D'Silva et al. (2011) at 1.5\% (w/w) of the starch. Xanthan gum solution at $0.25 \%(\mathrm{w} / \mathrm{w})$ was added to $10 \%(\mathrm{w} / \mathrm{w})$ of starch which was suspended in distilled water to 
make up a total volume of $28 \mathrm{~g}$ for the whole system. Starch suspension of $10 \%(\mathrm{w} / \mathrm{w})$ with $1.5 \%$ (w/w starch) stearic acid and $0.25 \%$ (w/w starch) xanthan gum alone and in combination was pasted using the RVA. This pasting cycle began with an initial stirring of $960 \mathrm{rpm}$ at $50^{\circ} \mathrm{C}$ for $30 \mathrm{~s}$ and then $160 \mathrm{rpm}$ for the entire period thereafter. The temperature was increased to $90^{\circ} \mathrm{C}$ at a rate of $5.5^{\circ} \mathrm{C} / \mathrm{min}$ and held at this temperature for $2 \mathrm{~h}$. These pasted starches were used for further analysis either fresh or freeze dried. The pastes were cooled to $50^{\circ} \mathrm{C}$ for 12 min at rate of $5.5^{\circ} \mathrm{C} / \mathrm{min}$ for texture and freeze-thaw stability determinations. Freeze dried samples were used for DSC and WAXS.

\subsubsection{Starch gel texture}

Textural properties were determined according to Bultosa and Taylor (2004) with modifications. Starch pastes were hot-filled into small, circular containers $(16 \mathrm{~mm}$ height $\mathrm{x}$ $37 \mathrm{~mm}$ diameter). The pasted starches were stored for $24 \mathrm{~h}$ at about $23 \pm 1^{\circ} \mathrm{C}$. Gel firmness and stickiness was analysed using EZ-test texture analyser EZ-L, Shimadzu (Tokyo, Japan) with $\mathrm{P} / 20 \mathrm{p}$ cylinder probe $(20 \mathrm{~mm}$ diameter). The probe penetrated $5 \mathrm{~mm}$ and retracted from the sample. The maximum and minimum force was noted. This was conducted at a pre-load force of $0.02 \mathrm{~N}$, pre-test speed of $50 \mathrm{~mm} / \mathrm{min}$ and test speed of $10 \mathrm{~mm} / \mathrm{min}$.

\subsubsection{Freeze thaw stability}

Freeze thaw stability was determined according to Sae-kang and Suphantharika (2006) with modifications. The starch pastes obtained from the RVA were transferred into screw-cap plastic centrifuge tubes. The starch samples were frozen at $-20^{\circ} \mathrm{C}$ for $22 \mathrm{~h}$ then thawed in a water bath at $30^{\circ} \mathrm{C}$ for $1 \mathrm{~h}$ and centrifuged at $3030 \mathrm{~g}$ for $10 \mathrm{~min}$. At the end of each thaw cycle, the amount of liquid separated was weighed. This procedure was repeated for ten consecutive cycles and \% phase separation at each cycle was calculated as: 
$\left(\frac{\text { Weight of separated liquid }}{\text { Original weight }}\right) \times 100$

\subsubsection{Flow properties}

Flow properties were determined according to D'Silva et al. (2011) with modifications. Flow properties were measured using the cup and bob method with a Physica MCR 101 Rheometer with Rheoplus software ${ }^{\circledR}$, (Anton Paar, Ostfildern, Germany). The starch pastes obtained from the RVA were transferred into the Rheometer set at $75^{\circ} \mathrm{C}$. The measuring bob (diameter: 27 $\mathrm{mm}$ ) was inserted into the cup (diameter: $28.9 \mathrm{~mm}$ ) containing the starch paste. To prevent moisture loss a solvent trap was used. Flow properties were determined at different shear rates from 0.1 to $800 \mathrm{~s}^{-1}$.

\subsubsection{Thermal properties}

Thermal properties of freeze-dried starches obtained after pasting were determined according to Wokadala et al. (2012) using high pressure Differential Scanning Calorimetry (DSC) system, HP DSC827 ${ }^{\mathrm{e}}$, Mettler Toledo (Greifensee, Switzerland). The freeze dried starch pastes powder $(7 \mathrm{mg})$ was mixed with distilled water $(21 \mathrm{mg})$ and then equilibrated for at least $4 \mathrm{~h} \mathrm{at}$ about $23 \pm 1^{\circ} \mathrm{C}$. Scanning was done from 25 to $170^{\circ} \mathrm{C}$ under pressure $\left(4 \mathrm{MPa}\right.$ using $\mathrm{N}_{2}$ ) at a

rate of $10^{\circ} \mathrm{C} / \mathrm{min}$. Indium $\left(\mathrm{T}_{\mathrm{p}}=156.6^{\circ} \mathrm{C}, 28.45 \mathrm{Jg}^{-1}\right)$ was used as a standard to calibrate DSC and an empty pan as reference.

\subsubsection{Wide angle $X$-ray diffraction scattering}

Wide angle X-ray diffraction scattering (WAXS) study was conducted using X'Pert PANalytical diffractometer (Eindhoven, Netherlands) on raw starch samples and freeze dried starch pastes. The freeze-dried starch samples were gently ground to fine powder. The raw and freeze-dried starch samples were equilibrated for 5 days at $95 \%$ equilibrium relative humidity (ERH) at about $23 \pm 1^{\circ} \mathrm{C}$ using glycerol. The XRD operating conditions were: $45 \mathrm{kV}, 40 \mathrm{~mA}$ and $\mathrm{CuK} \alpha 1(0.154 \mathrm{~nm})$. Scanning was done from $5^{\circ}$ to $30^{\circ}(2 \theta)$ and the exposure time was 16 min and $14 \mathrm{~s}$, step size was $0.026^{\circ}$ and time/step ratio was $229.5 \mathrm{~s}$. The relative degree of 
crystallinity was determined as the percentage integrated area of crystalline peaks to the total integrated area above a straight baseline (Wokadala et al., 2012).

\subsubsection{Statistical analysis}

The individual starches were analysed separately and factorial analysis of variance (ANOVA) was used with stearic acid and xanthan gum concentration as independent variables. Means were compared using Fischer's Least Significant Test (LSD) at 5\% level of significance using Statistica version 12 software, StatSoft, Inc (Tulsa, Oklahoma). Experiments were repeated three times.

\section{Results and discussion}

Figure 1 shows the pasting properties of maize, wheat, teff and cassava starches with addition of stearic acid and xanthan gum alone and in combination. The control (no stearic acid and xanthan gum) cereal starches (maize, wheat and teff) showed a first peak viscosity during heating to $90^{\circ} \mathrm{C}$ followed by another increase in viscosity during holding at $90^{\circ} \mathrm{C}$. Similar results have been reported for maize starch (Nelles et al., 2000) and teff starch (D'Silva et al., 2011). The increase in viscosity for cereal starches can be due to the presence of complexes formed between amylose and endogenous lipid as discussed later (Nelles et al., 2000). Cassava starch without the additives also showed a peak viscosity during heating, but there was no increase in viscosity during holding at $90^{\circ} \mathrm{C}$. The peak viscosity for cassava starch was higher and this peak was followed by a significant breakdown in viscosity compared to cereal starches. This may be attributed to the low amylose content in cassava starch and weak intragranular organization within the starch granule (Nwokocha, Aviara, Senan \& Williams, 2009). Kim, Patel and BeMiller (2013) showed that the breakdown in viscosity decreases with an increase in amylose content. It was speculated that this is because as the amylose content increases; swelling of the starch granules is reduced and the granules are less fragile. This would explain highest breakdown viscosity for cassava starch. However it is worth noting that the effects of structural properties on the pasting properties of starches are complex, as pasting 
properties are not only affected by amylose and lipids but also by the branch chain length distribution of amylopectin (Jane et al., 1999).
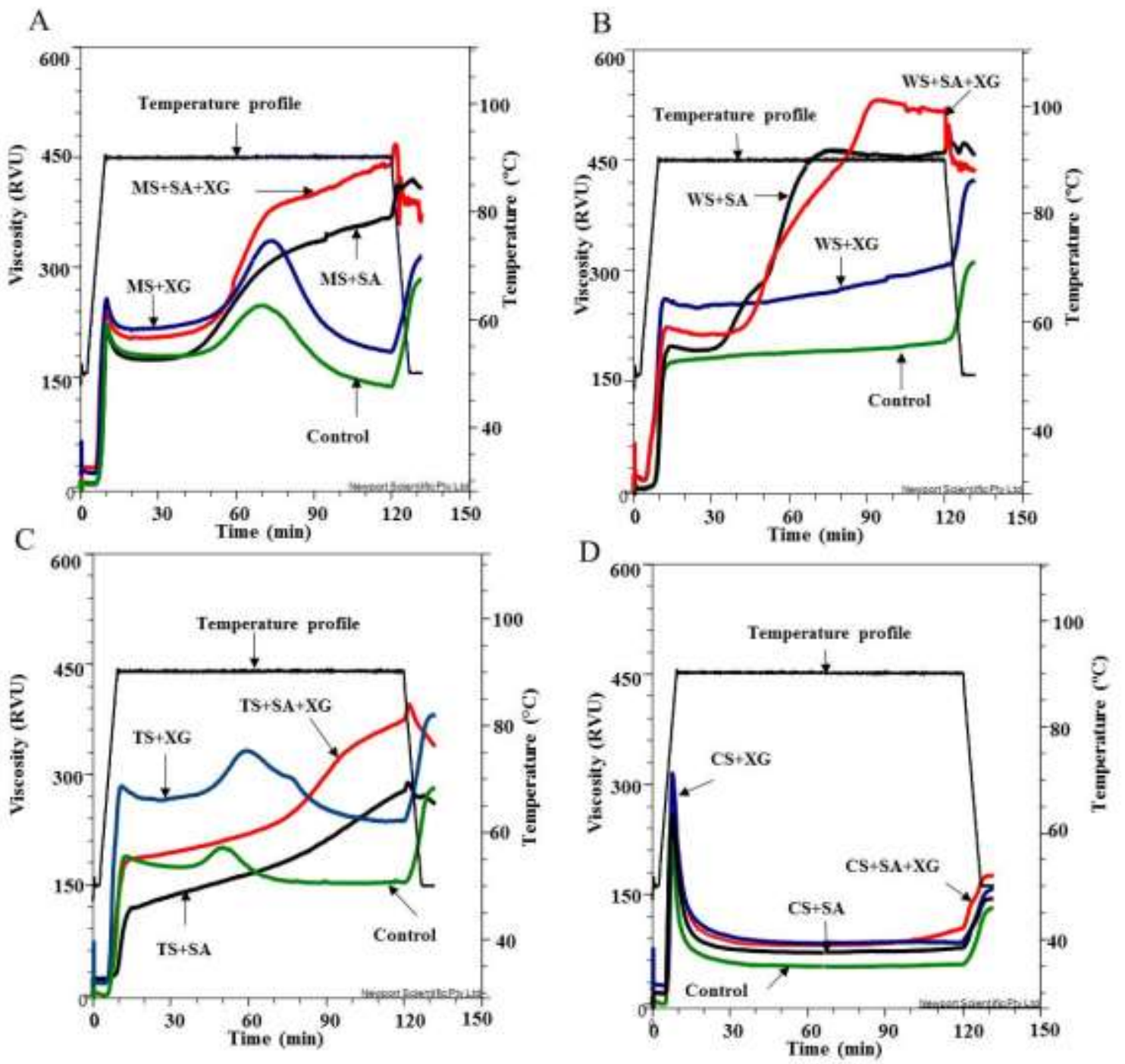

Fig. 1: Effect of xanthan gum and stearic acid alone and in combination on the pasting properties of (A) maize, (B) wheat, (C) teff and (D) cassava starches

$\mathrm{SA}$ is Stearic acid $(1.5 \% \mathrm{w} / \mathrm{w}$ of starch)

XG is Xanthan gum $(0.25 \%$ w/w of starch)

Control is no $\mathrm{SA}$ and $\mathrm{XG}$ addition

MS is Maize starch, WS is Wheat starch, TS is Teff starch, CS is Cassava starch

Each pasting curve is a representative of 3 repeats of experiment 
Table 1: Effects of stearic acid (SA) and xanthan gum (XG) alone and in combination on the textural and flow properties of maize, wheat, teff and cassava starches

\begin{tabular}{|c|c|c|c|c|c|c|c|}
\hline \multirow[b]{2}{*}{ Type of starch } & \multirow[b]{2}{*}{$\begin{array}{l}\text { SA } \\
(\mathrm{w} / \mathrm{w} \%)\end{array}$} & \multirow[b]{2}{*}{$\begin{array}{l}X G \\
(w / w \%)\end{array}$} & \multirow[b]{2}{*}{$\begin{array}{l}\text { Visual } \\
\text { perception }\end{array}$} & \multirow[b]{2}{*}{ Max Force (N) } & \multicolumn{3}{|c|}{ Upward curve ${ }^{* *}$} \\
\hline & & & & & $K\left(\mathrm{~Pa} \mathrm{~s}^{n}\right)$ & $n$ & $\begin{array}{l}\text { Hysteresis area } \\
\text { (Pas) }\end{array}$ \\
\hline \multirow[t]{4}{*}{ A:Maize starch } & 0 & 0 & Gel & $4.38^{\mathrm{b}} \pm 0.28$ & $63^{\mathrm{a}} \pm 2.5$ & $0.25^{\mathrm{c}} \pm 0.00^{*}$ & $18816^{\mathrm{a}} \pm 1129$ \\
\hline & 0 & 0.25 & Gel & $4.36^{b} \pm 0.50$ & $100^{\mathrm{b}} \pm 5.0$ & $0.21^{b} \pm 0.00^{*}$ & $15703^{a} \pm 105$ \\
\hline & 1.5 & 0 & Paste & $0.65^{\mathrm{a}} \pm 0.02$ & $156^{\mathrm{c}} \pm 0.1$ & $0.21^{b} \pm 0.00^{*}$ & $61958^{\mathrm{b}} \pm 13925$ \\
\hline & 1.5 & 0.25 & Paste & $0.40^{\mathrm{a}} \pm 0.01$ & $180^{\mathrm{d}} \pm 17.7$ & $0.13^{\mathrm{a}} \pm 0.00^{*}$ & $17225^{\mathrm{a}} \pm 364$ \\
\hline \multirow[t]{4}{*}{ B:Wheat starch } & 0 & 0 & Gel & $7.98^{\mathrm{d}} \pm 0.97$ & $51^{\mathrm{a}} \pm 1.9$ & $0.29^{c} \pm 0.02$ & $12238^{\mathrm{ab}} \pm 436$ \\
\hline & 0 & 0.25 & Gel & $6.72^{c} \pm 0.29$ & $83^{b} \pm 0.3$ & $0.25^{\mathrm{b}} \pm 0.01$ & $1673^{\mathrm{a}} \pm 96$ \\
\hline & 1.5 & 0 & Paste & $0.92^{b} \pm 0.08$ & $234^{\mathrm{d}} \pm 5.3$ & $0.14^{\mathrm{a}} \pm 0.02$ & $93214^{\mathrm{c}} \pm 9317$ \\
\hline & 1.5 & 0.25 & Paste & $0.72^{\mathrm{a}} \pm 0.07$ & $166^{c} \pm 13.7$ & $0.21^{\mathrm{b}} \pm 0.04$ & $26510^{\mathrm{b}} \pm 7950$ \\
\hline \multirow[t]{4}{*}{ C:Teff starch } & 0 & 0 & Gel & $3.88^{\mathrm{b}} \pm 0.14$ & $61^{\mathrm{a}} \pm 4.0$ & $0.24^{\mathrm{c}} \pm 0.01$ & $21539^{b} \pm 1273$ \\
\hline & 0 & 0.25 & Gel & $5.14^{\mathrm{c}} \pm 0.14$ & $87^{\mathrm{ab}} \pm 5.1$ & $0.23^{c} \pm 0.01$ & $22368^{\mathrm{b}} \pm 430$ \\
\hline & 1.5 & 0 & Paste & $0.21^{\mathrm{a}} \pm 0.02$ & $106^{b c} \pm 16.3$ & $0.17^{\mathrm{a}} \pm 0.01$ & $20122^{\mathrm{b}} \pm 1350$ \\
\hline & 1.5 & 0.25 & Paste & $0.20^{\mathrm{a}} \pm 0.01^{*}$ & $127^{\mathrm{c}} \pm 11.4$ & $0.20^{\mathrm{b}} \pm 0.01$ & $14489^{a} \pm 1175$ \\
\hline \multirow[t]{4}{*}{ D:Cassava starch } & 0 & 0 & Paste & $0.17^{\mathrm{b}} \pm 0.01$ & $15^{\mathrm{a}} \pm 0.3$ & $0.40^{\mathrm{b}} \pm 0.01$ & $-12042^{c} \pm 629$ \\
\hline & 0 & 0.25 & Paste & $0.22^{c} \pm 0.01$ & $19^{\mathrm{a}} \pm 1.5$ & $0.38^{b} \pm 0.03$ & $-20248^{d} \pm 1357$ \\
\hline & 1.5 & 0 & Paste & $0.14^{\mathrm{a}} \pm 0.01$ & $43^{b} \pm 3.9$ & $0.25^{\mathrm{a}} \pm 0.02$ & $7833^{b} \pm 2137$ \\
\hline & 1.5 & 0.25 & Paste & $0.13^{\mathrm{a}} \pm 0.01 *$ & $61^{c} \pm 6.8$ & $0.21^{\mathrm{a}} \pm 0.02$ & $2937^{\mathrm{a}} \pm 66$ \\
\hline
\end{tabular}

Means with different superscripts differ significantly per starch $(\mathrm{p}<0.05)$

SA is Stearic acid, $\mathrm{XG}$ is Xanthan gum

${ }^{\#}$ Visual perception of pasted starch left for $24 \mathrm{~h}$ at $23 \pm 1^{\circ} \mathrm{C}$, starch is consider as a gel when it cannot pour out freely or be spread on a surface and a paste is the opposite

*Interaction effect between stearic acid and xanthan gum, ${ }^{* *}$ Upward curve is increasing shear rate from 0.1 to $800 \mathrm{~s}^{-1}$

* Standard deviation less than 0.00 
The addition of stearic acid showed a further increase in viscosity during holding at $90^{\circ} \mathrm{C}$ for the cereal starches, and these viscosities were far higher than their peak viscosities during heating (Fig. 1). Although cassava starch showed a small increase in viscosity with stearic acid addition, this viscosity was not significantly $(\mathrm{p}>0.05)$ higher than its peak viscosity. The significant $(\mathrm{p}<0.05)$ increase in viscosity with stearic acid addition to the cereal starches is also reflected in the consistency coefficient $K$ for all the starches (Table 1). Table 1 also shows that the cereal starches with stearic acid had higher consistency compared to cassava starch. The increase in viscosity of maize and teff starches with addition of stearic acid has been reported by D'Silva et al. (2011) and Wokadala et al. (2012). This was attributed to the interaction between amylose and lipids resulting in the formation of amylose-lipid complexes. The absence of a second pasting peak during pasting for cassava starch with stearic acid may be attributed to the structure of its amylose which has been reported to have more branched in comparison to maize and wheat starches (Takeda, Hizukuri, Takeda \& Suzuki, 1987).

The pasting viscosity trend for all starches with xanthan gum was similar to their controls, except that pasting viscosity was significantly $(\mathrm{p}<0.05)$ higher (Fig. 1). An increase in viscosity has also been reported for maize, rice and cassava starches with xanthan gum during pasting (Shi \& BeMiller, 2002). Xanthan gum can form entanglements with amylose (Ferrero, Martino \& Zaritzky, 1994). The increase in viscosity is probably due to amylose-gum interactions (Shi \& BeMiller, 2002) promoted by hydrogen bonding (Weber et al., 2009). According to Kim et al. (2013), paste properties of starch are determined greatly by the amylose content rather than the added hydrocolloid. This could be the reason for the similar trend observed for starches with xanthan gum and their controls. Hong et al. (2015) suggested that xanthan gum is more likely to interact with amylose molecules as the increase in amylose content of maize starch showed more effects in terms of pasting properties. This is also shown in table 1 where cassava starch has the least increase in viscosity compared to the cereal starches with higher amylose content.

The addition of stearic acid and xanthan gum in combination to the cereal (maize, wheat and teff) starches during pasting showed similar viscous behaviour during pasting compared to addition of stearic acid alone (Fig. 1). However the viscosity was significantly $(\mathrm{p}<0.05)$ 
higher during holding at $90^{\circ} \mathrm{C}$ for those with stearic acid and xanthan gum in combination. This is also shown by higher consistency of the pasted starches (consistency coefficient, $K$ ) from flow property determination with combination of stearic acid and xanthan gum compared to stearic acid alone (Table 1). Thus it can be suggested that there are chemical interactions between these starches, xanthan gum and stearic acid to produce a higher viscosity during pasting. The mechanism of interaction is discussed later. Cassava starch did not show any significant $(\mathrm{p}>0.05)$ increase when pasted with stearic acid and xanthan gum in combination compared to the additives alone. In addition cassava starch had a low viscosity of about 100 RVU during holding at $90^{\circ} \mathrm{C}$ or less compared to the cereal starches that were over $150 \mathrm{RVU}$ for the control and over 300 up to $500 \mathrm{RVU}$ for the cereal starches with stearic acid and xanthan gum during holding at $90^{\circ} \mathrm{C}$.

The pasting properties during cooling from 90 to $50^{\circ} \mathrm{C}$ showed differences between the treatments (Fig. 1). There was a further increase in viscosity for cereal starches without the additives and with xanthan gum for the cereal starches. However the addition of stearic acid alone and in combination with xanthan gum showed a very small increase or no increase during cooling. These results are also reflected with the gelling behaviour of the cereal starches (Table 1). Cereal starches with no additives and with xanthan gum alone showed a gel behaviour with higher penetration force of the gels compared to paste like behaviour with penetration force of less than $1 \mathrm{~N}$ for stearic acid alone and combination of stearic acid and xanthan gum. Similar results reported here have been reported by D'Silva et al. (2011) for maize and teff starches with stearic acid. The presence of a complexing agent can increase spacing between junction zones (Blazek \& Copeland, 2009). This may result in lower viscosity increase during cooling. Pasted starches with lipids are softer and easy to penetrate compared to those without lipids (Blazek \& Copeland, 2009).

Although cassava starches showed a slight increase in viscosity during cooling with and without the additives, they were all paste-like in behaviour with maximum penetration force of less than $0.25 \mathrm{~N}$ (Table 1). Similar findings for cassava starches have been reported during pasting (Peroni, Rocha \& Franco, 2006; Nwokocha et al., 2009).These results suggest that 
cereal starches pasted with stearic acid alone and in combination with xanthan gum can have similar rheological behaviour in terms of non-gelling like cassava starches.

To further understand the interaction of maize, wheat, teff and cassava starches with stearic acid and xanthan gum alone and in combination, further analyses were conducted including freeze-thaw stability, hysteresis during flow property measurement, Differential scanning calorimetry (DSC) and wide angle x-ray diffraction scattering (WAXS).

Fig. 2 and Table 1 show the freeze-thaw stability and flow properties of maize, wheat, teff and cassava starches with stearic acid and xanthan gum alone and in combination. The initial phase separation for maize, teff and cassava starch controls was observed after the fourth, ninth and fifth freeze-thaw cycle respectively. The amount of water separated for maize, teff and cassava starch controls at the tenth freeze-thaw cycles were about $15.6 \%, 2.4 \%$ and $22.4 \%$ respectively. Bultosa and Taylor (2004) also showed that teff starch had lower amount of water separated for three freeze-thaw cycles compared to maize starch. This was related to the smaller radius of gyration as a well a shorter A and B1 chains for teff amylopectin compared to maize amylopectin molecules (Bultosa, Hamaker \& Bemiller, 2008). Cassava starch has been reported to be more freeze-thaw stable in comparison to maize starches (Srichuwong, Isono, Jiang, Mishima \& Hisamatsu, 2012). Srichuwong et al. (2012) reported that a lower amylose content reduces the syneresis tendency of starch gels. Flow property measurements showed that the hysteresis area was higher for teff starch (about 21539 Pas) compared to maize and wheat starch controls (about 18816 and 12238 Pas respectively). A negative hysteresis area (about -12042 Pas) was observed for cassava starch (Table 1). Cassava starch has been reported to show counter clockwise hysteresis loop (Temsiripong, Pongsawatmanit, Ikeda \& Nishinari, 2005; Sikora, Kowalski \& Tomasik, 2008), this suggested that there could be time dependent structure building under shear (Temsiripong et al., 2005). This showed that cassava starch was more stable to shear compared to cereal starches.

All the starches with stearic acid had higher phase separation during freeze-thaw cycles compared to the controls (Fig. 2). The amount of water separated for maize, wheat, teff and cassava starches with stearic acid alone at the tenth freeze-thaw cycles were about $47.9 \%$, 
$40.1 \%, 59.4 \%$ and $33.8 \%$ respectively. These were higher compared to their respective controls (Fig. 2). A significant increase $(\mathrm{p}<0.05)$ in the hysteresis area was also observed for maize and wheat starch with stearic acid addition compared to the controls (Table 1). If a hysteresis loop area is assumed to be an index of the energy required to break down the structure under shear, then samples with high viscosity would require more energy (Tárrega, Durán \& Costell, 2004). This would explain the increase in hysteresis area for starches with stearic acid as they had higher viscosity. These results suggest that the addition of stearic acid to maize, wheat, teff and cassava starch reduced the stability to freezing and shear.

A

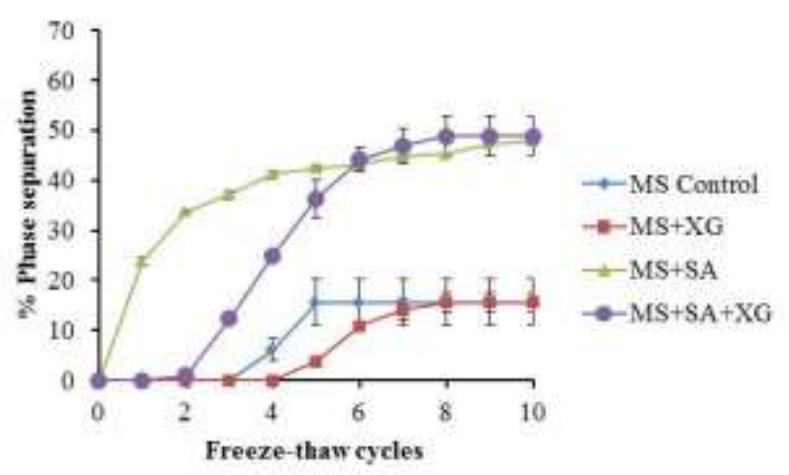

$\mathrm{C}$

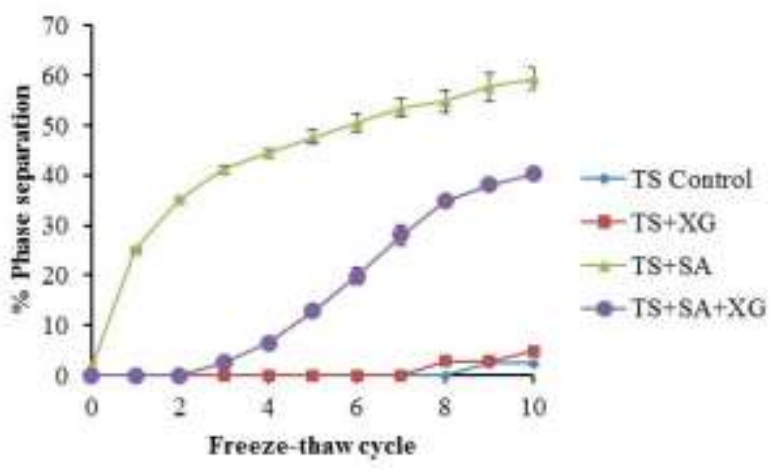

B

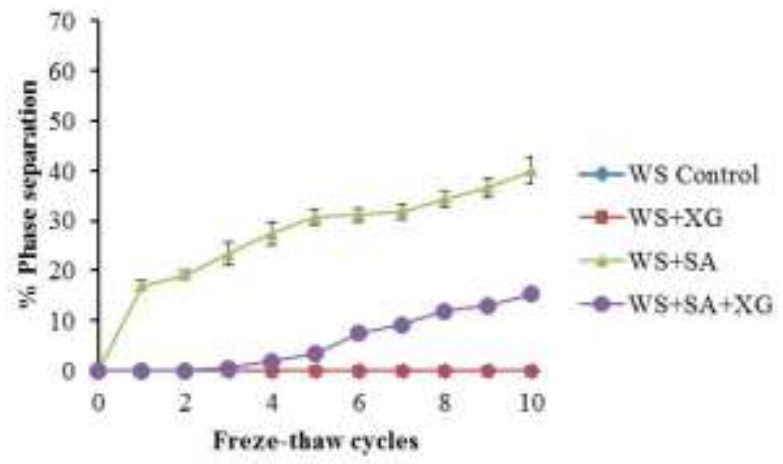

D

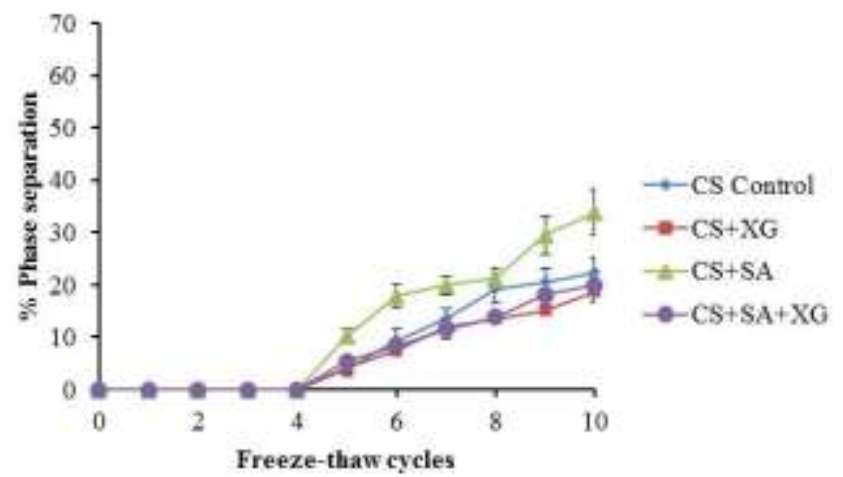

Fig. 2: Freeze-thaw stability of (A) maize, (B) wheat, (C) teff and (D) cassava starch controls, with stearic acid, xanthan gum and combination of stearic acid and xanthan gum after 10 freeze-thaw cycles

$\mathrm{SA}$ is Stearic acid (1.5\% w/w of starch)

$\mathrm{XG}$ is Xanthan gum $(0.25 \% \mathrm{w} / \mathrm{w}$ of starch)

Control is no $\mathrm{SA}$ and $\mathrm{XG}$ addition

MS is Maize starch, WS is Wheat starch, TS is Teff starch, CS is Cassava starch

Error bars indicate standard deviation 
The amount of water separated for maize, teff and cassava starches with xanthan gum alone at the tenth freeze-thaw cycles were about $15.6 \%, 4.8 \%$ and $18.8 \%$ respectively (Fig. 2). This trend is similar to their respective controls except that the amount of water separated for cassava starch with xanthan gum was lower compared to the control. Kim et al. (2013) showed that amylose content of starch is a greater determinant of paste and gel properties than the added hydrocolloid. However the amylopectin chains length have also been reported to affect starch gel retrogradation during freeze-thaw cycles as was observed for teff and maize starches (Bultosa \& Taylor, 2004; Bultosa et al., 2008). A decrease in the amount of water separated has been reported for cassava starch with $0.25 \%$ xanthan gum (Muadklay \& Charoenrein, 2008). Xanthan gum may minimise freeze-thaw damage by reducing the available water to form ice crystals (Pongsawatmanit \& Srijunthongsiri, 2008). Xanthan gum may also reduce amylose-amylose interactions for retrogradation by forming xanthan gum-amylose entanglements (Ferrero et al., 1994). This suggested that the addition of xanthan gum increased physical stability of cassava starch to freezing conditions. Cassava starch with xanthan gum showed similar negative hysteresis area as the cassava control (no additives), but this negative hysteresis increased with xanthan gum addition (Table 1). The negative hysteresis area between starch and xanthan gum has been attributed to interactions between xanthan gum and amylose during shear flow (Korus, Juszczak, Witczak \& Achremowicz, 2004).

A combination of stearic acid and xanthan gum to wheat, teff and cassava starches reduced phase separation compared to starches with stearic acid alone (Fig. 2). The amount of water separated for maize, wheat, teff and cassava starches with stearic acid and xanthan gum in combination at the tenth freeze-thaw cycles were about $48.8 \%, 15.3 \%, 40.4 \%$ and $19.9 \%$. The decrease in the amount of water separated may be attributed to the decrease in the amount of water available to form ice crystals due to xanthan gum addition (Pongsawatmanit \& Srijunthongsiri, 2008). In addition, a significant decrease $(\mathrm{p}<0.05)$ in the hysteresis area to about 17225, 26510, 14489 and 2937 Pas was observed for maize, wheat, teff and cassava starches with stearic acid and xanthan gum in combination compared with stearic acid alone (Table 1). This showed that the addition of xanthan gum to starches with stearic acid increased the stability to freezing and shear. 
Fig. 3 shows the thermal properties of maize, wheat, teff and cassava starches with stearic acid and xanthan gum alone and in combination. Maize, wheat and teff starch controls showed one endotherm with temperature range of about $99.5-111.5^{\circ} \mathrm{C}, 97.4-105.2^{\circ} \mathrm{C}$ and $98.4-108.4^{\circ} \mathrm{C}$ with $\Delta H$ of about $0.4 \mathrm{~g}^{-1}, 0.1 \mathrm{Jg}^{-1}$ and $0.3 \mathrm{Jg}^{-1}$ (Fig. 3). Cassava starch control did not show endothermic peaks (Fig. 3). The endothermic peaks for pasted starches with xanthan gum were similar to their controls.

Maize starch with stearic acid had endotherms with temperature ranges of about $63.2-69.4^{\circ} \mathrm{C}$, $107.7-114.3^{\circ} \mathrm{C}$ and $115.7-122.0^{\circ} \mathrm{C}$ with $\Delta H$ of about $0.5 \mathrm{Jg}^{-1}, 0.5 \mathrm{Jg}^{-1}$ and $0.2 \mathrm{Jg}^{-1}$ (Fig. 3). Wheat starch with stearic acid had endotherms with temperature ranges of about 105.9$113.9^{\circ} \mathrm{C}$ and $115.2-122.7^{\circ} \mathrm{C}$ with $\Delta H$ of about $1.0 \mathrm{Jg}^{-1}$ and $0.9 \mathrm{Jg}^{-1}$. Teff starch with stearic acid had endotherms with temperature ranges of about $97.9-105.6^{\circ} \mathrm{C}, 107.8-113.5^{\circ} \mathrm{C}$ and 115.0-121.5 ${ }^{\circ} \mathrm{C}$ with $\Delta H$ of about $0.4 \mathrm{Jg}_{-}{ }^{1}, 0.4 \mathrm{Jg}^{-1}$ and $0.1 \mathrm{Jg}^{-1}$. Multiple endotherms have previously been reported in starches containing added monoglycerides or fatty acids (Biliaderis \& Galloway, 1989; Karkalas, Ma, Morrison \& Pethrick, 1995; Wokadala et al., 2012). Endotherms with dissociation temperatures of about $98^{\circ} \mathrm{C}, 106^{\circ} \mathrm{C}$ and $120^{\circ} \mathrm{C}$ correspond to type I, type IIa and type IIb complexes respectively (Biliaderis \& Galloway, 1989; Karkalas et al., 1995). Cassava starch with stearic acid had an endotherm with temperature range of about $62.8-71.8^{\circ} \mathrm{C}$ with $\Delta H$ of about $0.94 \mathrm{Jg}^{-1}$ (Fig. 3). This endotherm corresponded to stearic acid, indicating the presence of free or uncomplexed stearic acid as pure stearic acid has an endotherm with peak temperatures of $69^{\circ} \mathrm{C}$ (Wokadala et al., 2012).

Maize starch with combination of stearic acid and xanthan gum had endotherms with temperature ranges of about $60.6-67.2^{\circ} \mathrm{C}, 96.5-105.1^{\circ} \mathrm{C}$ and $106.8-113.6^{\circ} \mathrm{C}$ with $\Delta H$ of about $0.2 \mathrm{Jg}^{-1}, 0.4 \mathrm{Jg}^{-1}$ and $0.6 \mathrm{Jg}^{-1}$ (Fig. 3). Wheat starch with combination of stearic acid and xanthan gum had endotherms with temperature ranges of about $105.8-113.0^{\circ} \mathrm{C}$ and 114.9 $120.0^{\circ} \mathrm{C}$ with $\Delta H$ of about $1.4 \mathrm{Jg}^{-1}$ and $0.3 \mathrm{Jg}^{-1}$. Teff starch with stearic acid and xanthan gum in combination had endotherms with temperature ranges of about $60.3-65.3^{\circ} \mathrm{C}, 96.9-106.0^{\circ} \mathrm{C}$ and $107.6-113.8^{\circ} \mathrm{C}$ with $\Delta H$ of about $0.4 \mathrm{Jg}^{-1}, 0.9 \mathrm{Jg}^{-1}$ and $0.6 \mathrm{Jg}^{-1}$ (Fig. 3). The $\Delta H$ for endothermic peak with temperature range of about $99.5-116.7^{\circ} \mathrm{C}$ for maize and teff starches with combination of stearic acid and xanthan gum was comparable to the sum of $\Delta H$ for 


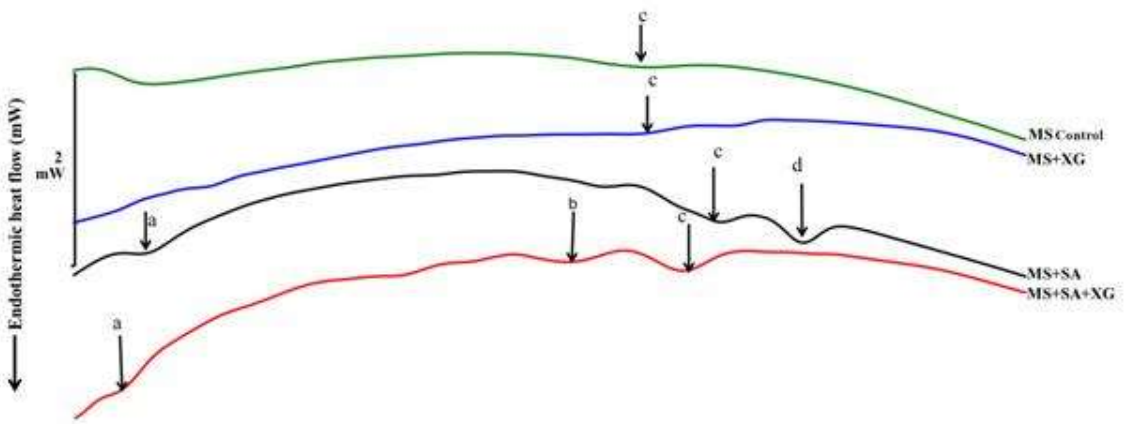

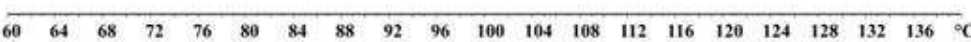

Temperature $\left({ }^{\circ} \mathrm{C}\right)$

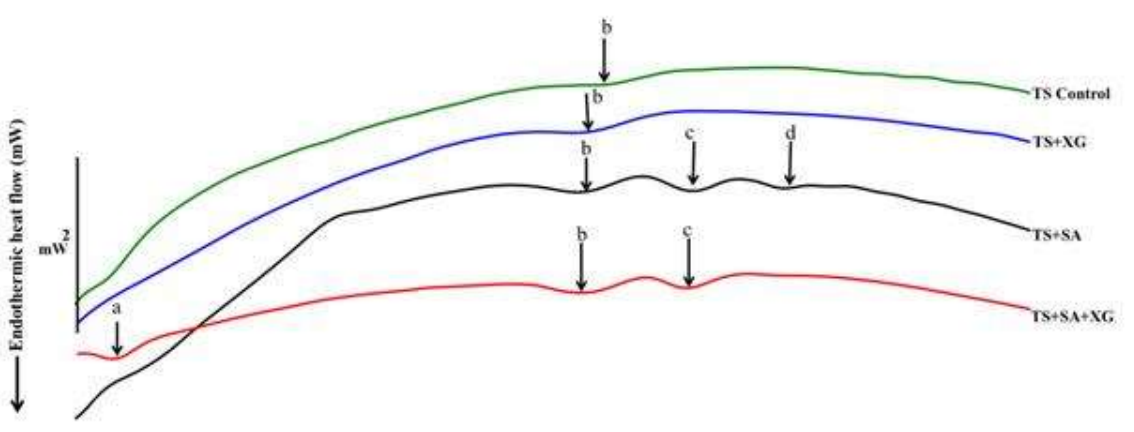

$\begin{array}{llllllllllllllllllllll}60 & 64 & 68 & 72 & 76 & 80 & 84 & 88 & 92 & 96 & 100 & 104 & 108 & 112 & 116 & 120 & 124 & 128 & 132 & 136 & { }^{\circ} \mathrm{C}\end{array}$ Temperature ${ }^{\circ} \mathrm{C}$
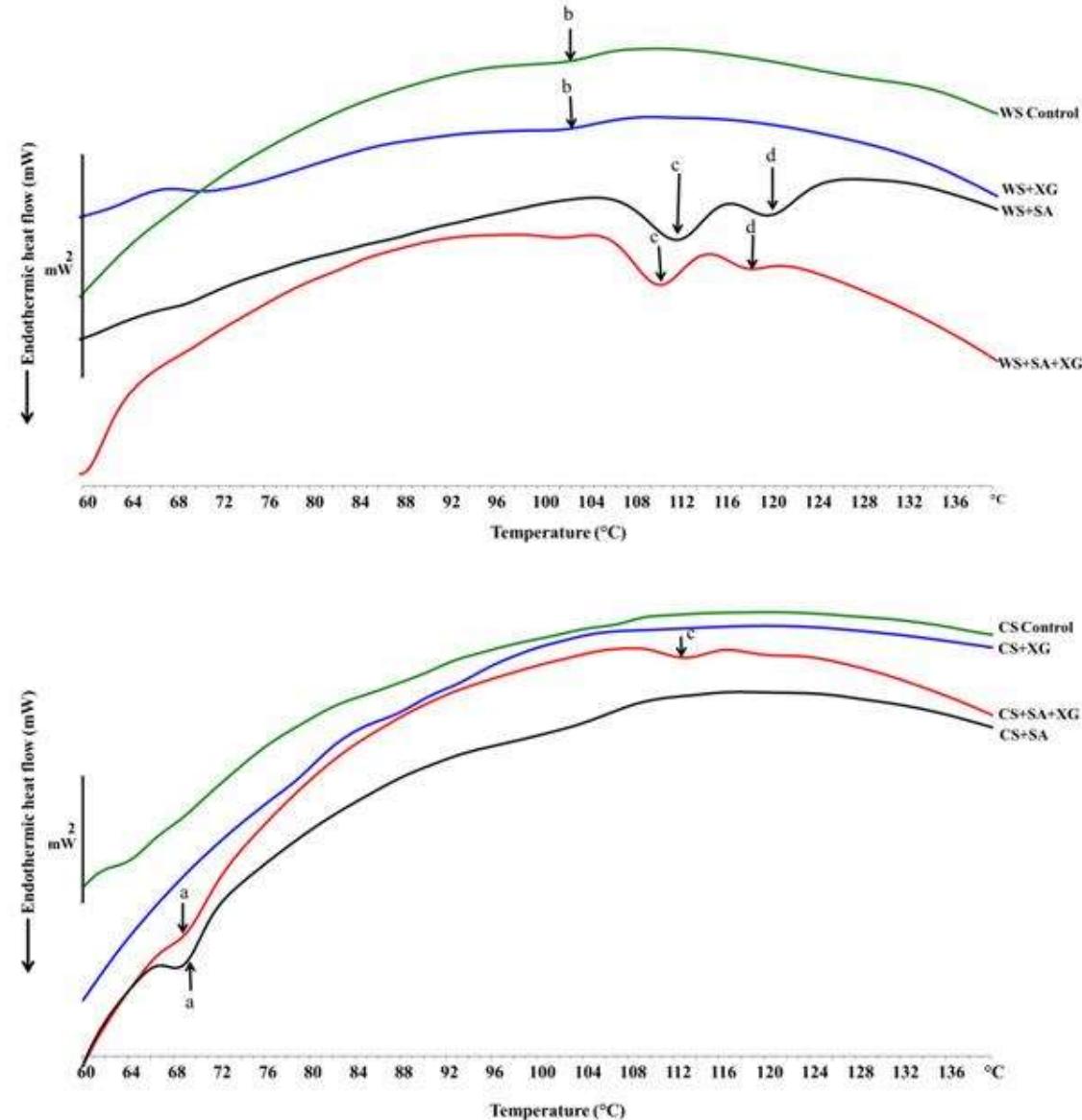

Temperature $(\circ)$

Fig. 3: Effect of stearic acid and xanthan gum alone and in combination on the thermal properties of (A) maize, (B) wheat, (C) teff and (D) cassava starches after pasting

$\mathrm{SA}$ is Stearic acid $(1.5 \% \mathrm{w} / \mathrm{w}$ of starch)

$\mathrm{XG}$ is Xanthan gum $(0.25 \% \mathrm{w} / \mathrm{w}$ of starch)

Control is no SA and $\mathrm{XG}$ addition

MS is Maize starch, WS is Wheat starch, TS is Teff starch, CS is Cassava starch

a corresponds to endotherms with temperature range of about $60.3-71.8, \mathrm{~b}$ corresponds to endotherms with temperature range of about $95.5-108.4^{\circ} \mathrm{C}, \mathrm{c}$ corresponds to endotherms with temperature range of about $99.5-116.7^{\circ} \mathrm{C}, \mathrm{d}$ corresponds to endotherms with temperature range of about $114.9-122.7^{\circ} \mathrm{C}$ 
endothermic peaks with temperature range of about $99.5-116.7^{\circ} \mathrm{C}$ and about $114.9-122.7^{\circ} \mathrm{C}$ for maize and teff starches with stearic acid alone. The sum of $\Delta H$ for endothermic peaks with temperature range of about $99.5-116.7^{\circ} \mathrm{C}$ and about $114.9-122.7^{\circ} \mathrm{C}$ for wheat starch with stearic acid alone and in combination with xanthan gum were comparable (Fig. 3). Type IIa and type IIb amylose-lipid complexes indicate progressive development to larger and more perfect crystallites upon annealing (Biliaderis \& Galloway, 1989). DSC results indicated that a combination of stearic acid and xanthan gum reduced the formation of type IIb amylose-lipid complexes as there was less or smaller endotherms at about $120^{\circ} \mathrm{C}$. It is suggested that xanthan gum interacts with amylose-lipid helices to prevent aggregation of type IIa to form type IIb. Cassava starch with stearic acid and xanthan gum in combination had endotherms with temperature ranges of $65.4-71.7^{\circ} \mathrm{C}$ and $109.1-116.7^{\circ} \mathrm{C}$ with $\Delta H$ of $0.47 \mathrm{Jg}^{-1}$ and $0.51 \mathrm{Jg}^{-1}(\mathrm{Fig}$. 3). The $\Delta H$ for the endothermic peak with temperature ranges of $65.4-71.7^{\circ} \mathrm{C}$ for cassava starch with combination of stearic acid and xanthan gum was lower compared with stearic acid alone.

Fig. 4 and 5 shows the wide angle x-ray diffractogram of maize, wheat, teff and cassava starches with stearic acid and xanthan gum alone and in combination before and after pasting. Wide angle x-ray diffraction (WAXS) showed that all the unpasted starches with and without stearic acid and xanthan gum alone and in combination showed characteristics of A-type crystalline pattern with major peaks at diffraction angle $2 \theta$ of about $15^{\circ}, 16^{\circ}, 19^{\circ}$ and $22^{\circ}$ (Fig. 4). Maize (Cheetham \& Tao, 1998), wheat (Fujita,Yamamoto, Sugimoto, Morita \& Yamamori, 1998), teff (Bultosa \& Taylor, 2003) and cassava starches (Jane et al., 1999) have been reported to display A-type crystalline structure. Starches with A-type pattern show peaks at diffraction angle $2 \theta$ of about $15^{\circ}, 17^{\circ}, 18^{\circ}$ and $23^{\circ}$ (Cheetham \& Tao, 1998). However cassava starch has also been reported to show $\mathrm{C}_{\mathrm{A}^{-}}$-type crystalline pattern (Gomes, da Silva, Ricardo, Sasaki \& Germani, 2004). The A-type starches have short amylopectin chains whereas B-type starches have long amylopectin chains and C-type starches have intermediate chain lengths (Hizukuri, 1985). A positive correlation between amylopectin and the relative degree of crystallinity has been suggested (Cheetham \& Tao, 1998). Raw unpasted cassava starch control had the highest degree of crystallinity and wheat starch control had the lowest relative degree of crystallinity (Fig. 4). The relative degree of crystallinity decreases with an 
increase in the amylose content. Amylose content plays an important role in reducing the relative degree of crystallinity (Cheetham \& Tao, 1998).

After pasting, maize starch control had weak peaks at diffraction angle $2 \theta$ of about $12.6^{\circ}$, $16.0^{\circ}$ and $19.2^{\circ}$ (Fig. 5). Pasted wheat starch control showed minor peaks at $2 \theta$ of about $15.8^{\circ}$ and $19.1^{\circ}$. Pasted teff starch control showed weak peaks at $2 \theta$ of about $12.4^{\circ}$ and $19.3^{\circ}$ and pasted cassava starch showed a bell shaped curve (Fig. 5). WAXS for pasted starches with xanthan gum were similar to their controls (Fig. 5). The relative degree of crystallinity of these starches were lower in comparison to their unpasted starches. During heating of starch, gelatinisation takes place resulting in a transition from crystalline to an amorphous state (Colonna \& Mercier, 1985). However in the presence of a lipid, crystallites are formed due to amylose-lipid complexes as indicated by the DSC (Fig. 3) resulting in $\mathrm{V}_{\mathrm{h}}$-type crystalline pattern (Godet, Bizot \& Buléon, 1995).

Analysis from WAXS showed that pasted maize, wheat and teff starches with stearic acid showed more pronounced peaks at $2 \theta$ ranges of about $6.6-6.8^{\circ}, 12.1-12.8^{\circ}$ and $19.0-19.8^{\circ}$ (Fig. 5). When fatty acids are added to starch, amylose assumes a helical conformation with a hydrophobic cavity where the fatty acid hydrocarbon chain can fit in (Raphaelides, 1993). The presence of a lipid results in the formation of a stable V-amylose inclusion complex (López, de Vries \& Marrink, 2012). $\mathrm{V}_{\mathrm{h}}$-type amylose has major peaks at diffraction angles $2 \theta$ of about $7.4^{\circ}, 12.9^{\circ}, 19.8^{\circ}$ (Godet et al., 1995). The relative degree of crystallinity for the pasted cereal starches with stearic acid were lower than their respective unpasted starch controls (Fig. 4) but were higher than their respective pasted starch controls. Biliaderis and Galloway (1989) suggested that only type II amylose lipid complexes have a distinct V-amylose diffraction pattern. This is shown in the DSC results. Additional peaks at $2 \theta$ of about $20.6^{\circ}$ and $22.1^{\circ}$ was observed for maize and cassava starches with stearic acid and cassava starches also showed bell shaped curve X-ray diffractogram (Fig. 5). These peaks corresponded to stearic acid peak, indicating the presence of free or uncomplexed stearic acid as pure stearic acid has major peaks at diffraction angle $2 \theta$ of about $2^{\circ}, 7^{\circ}$ and $22^{\circ}$ (Lodha $\&$ Netravali, 2005). As discussed, the absence of a second pasting peak during pasting and absence amylose-lipid complex peaks as shown by DSC and WAXS (Fig. 3 and 5) for cassava starch with stearic acid may be 
attributed to the branched structure of its amylose (Takeda et al., 1987). The branched structure can limit complexation of amylose with lipids.
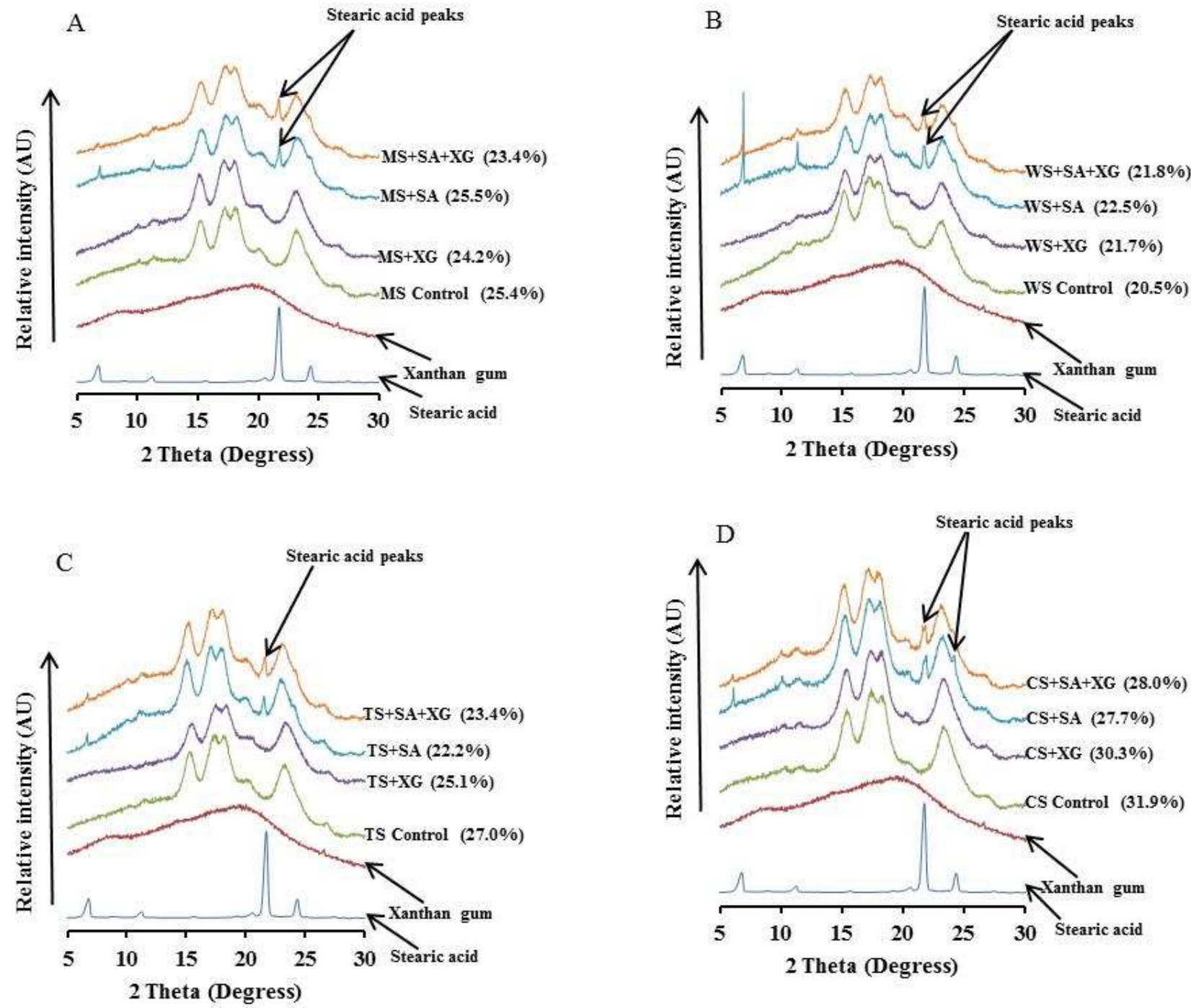

Fig. 4: Effects of stearic acid and xanthan gum alone and in combination on the X-ray diffactograms of maize, wheat, teff and cassava starches before pasting

$\mathrm{SA}$ is Stearic acid (1.5\% w/w of starch)

$\mathrm{XG}$ is Xanthan gum $(0.25 \% \mathrm{w} / \mathrm{w}$ of starch)

Control is no $\mathrm{SA}$ and $\mathrm{XG}$ addition

MS is Maize starch, WS is Wheat starch, TS is Teff starch, CS is Cassava starch

Values in parenthesis indicate the relative degree of crystallinity 
A

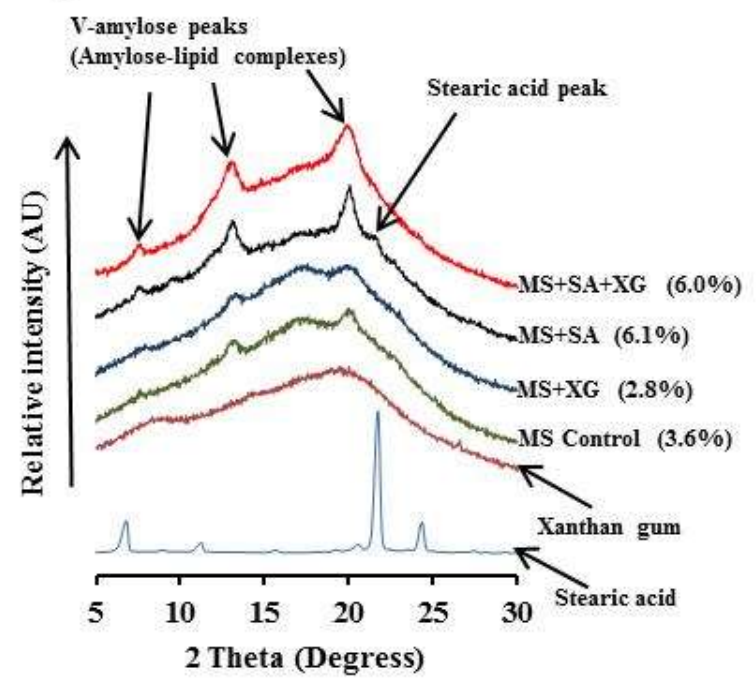

$\mathrm{C}$

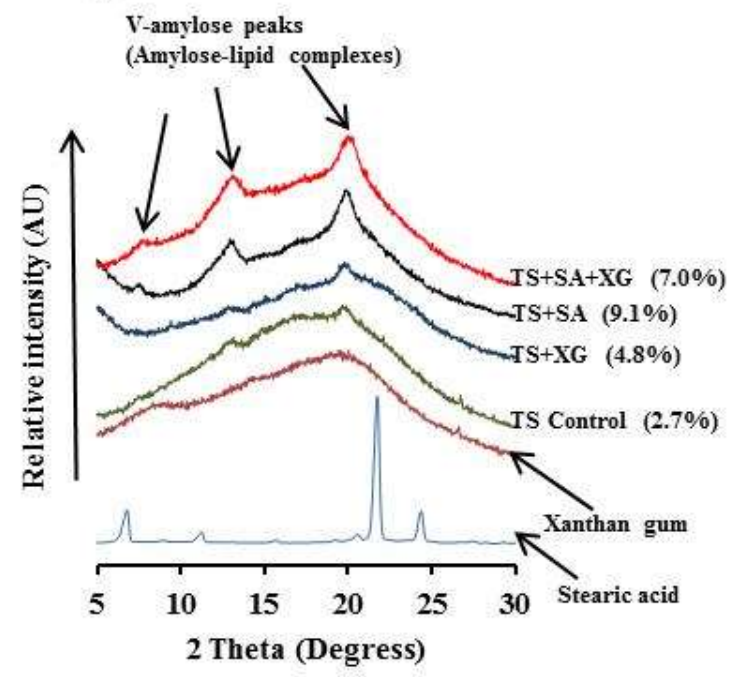

B

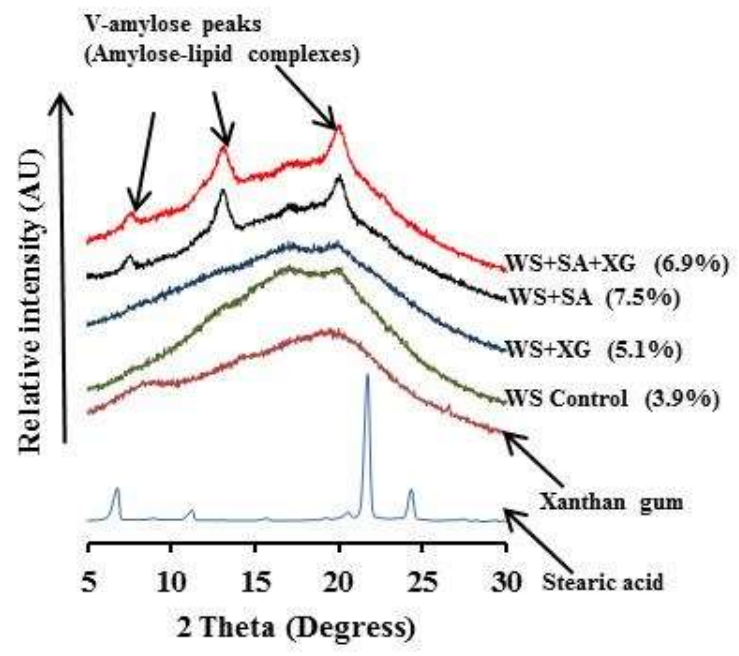

$\mathrm{D}$

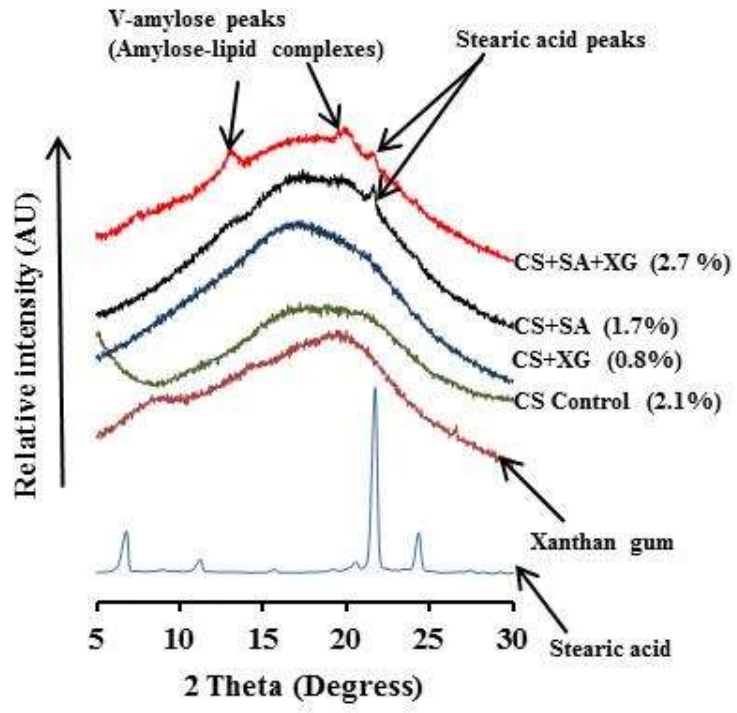

Fig. 5: Effects of stearic acid and xanthan gum alone and in combination on the X-ray diffactograms of maize, wheat, teff and cassava starches after pasting

SA is Stearic acid (1.5\% w/w of starch)

$\mathrm{XG}$ is Xanthan gum $(0.25 \% \mathrm{w} / \mathrm{w}$ of starch)

Control is no $\mathrm{SA}$ and $\mathrm{XG}$ addition

MS is Maize starch, WS is Wheat starch, TS is Teff starch, CS is Cassava starch

Values in parenthesis indicate the relative degree of crystallinity 
The results from WAXS showed that the peaks for pasted cereal starches with stearic acid and xanthan gum in combination were similar in their $2 \theta$ angles to starches with stearic acid alone, but the peaks appeared to be broader. Analyses from WAXS showed that pasted cassava starch with combination of stearic acid and xanthan gum had peaks at $2 \theta$ of about $12.5^{\circ}$ and $18.9^{\circ}$ and an additional peak at $2 \theta$ of about $20.7^{\circ}$ (Fig. 5). Although the values are lower compared to results reported by Godet et al. (1995) and Lodha and Netravali (2005), these peaks are suggested to correspond to $\mathrm{V}_{\mathrm{h}^{-}}$type amylose and the presence of pure stearic acid. The relative degree of crystallinity for the pasted cassava starch with combination of stearic acid and xanthan gum $(2.7 \%)$ was significantly higher $(\mathrm{p}<0.05)$ compared with stearic acid alone (1.7\%) (Fig. 5). These properties indicated the occurrence of few amylose-lipid complexes for cassava starch with stearic acid and xanthan gum in combination compared to cereal starches which had relative degree of crystallinity of about $6.0 \%$.

\section{Conclusions}

Stearic acid can produce high viscosity starches with a non-gelling behaviour and xanthan gum produce starches that are more stable to freezing and shear compared to stearic acid alone. A combination of stearic acid and xanthan gum can produce even higher viscosity starches that are stable to freezing compared to stearic acid alone. In addition, starches with stearic acid alone form type I, IIa and IIb amylose-lipid complexes but combination of stearic acid and xanthan gum reduce the formation of type IIb amylose-lipid complexes. The effects of a combination of stearic acid and xanthan gum on starch functionality may be attributed to interactions between xanthan gum and amylose-lipid helices and probably some interaction between free xanthan gum and free amylose and amylopectin.

\section{Acknowledgements}

The authors would like acknowledge to the National research foundation (NRF) and NRF/DST centre of excellence on food security, Winter cereal trust (WCT) and University of Pretoria research support for funding. The CSIR national centre for nano-structured materials for their assistance with WAXS. 


\section{References}

Arocas, A., Sanz, T., \& Fiszman, S. M. (2009). Clean label starches as thickeners in white sauces. Shearing, heating and freeze/thaw stability. Food Hydrocolloids, 23, 2031-2037.

Bahnassey, Y. A., \& Breene, W. M. (1994). Rapid Visco-Analyzer (RVA) pasting profiles of wheat, corn, waxy corn, tapioca and amaranth starches (A. hypochondriacus and A. cruentus) in the presence of konjac flour, gellan, guar, xanthan and locust bean gums. Starch/Stärke, 46, 134-141.

BeMiller, J. N. (2011). Pasting, paste, and gel properties of starch-hydrocolloid combinations. Carbohydrate Polymers, 86, 386-423.

Biliaderis, C. G., \& Galloway, G. (1989). Crystallization behavior of amylose-V complexes: structureproperty relationships. Carbohydrate Research, 189, 31-48.

Blazek, J., \& Copeland, L. (2009). Effect of monopalmitin on pasting properties of wheat starches with varying amylose content. Carbohydrate Polymers, 78, 131-136.

Brennan, C. S., Tan, C. K., Kuri, V., \& Tudorica, C. M. (2004). The pasting behaviour and freezethaw stability of native starch and native starch-xanthan gum pastes. International Journal of Food Science and Technology, 39, 1017-1022.

Bultosa, G., Hamaker B. R., \& BeMiller, J. N. (2008). An SEC-MALLS study of molecular features of water-soluble amylopectin and amylose of tef [Eragrostis tef (Zucc.) Trotter] starches. Starch/Stärke, $60,8-22$.

Bultosa, G., \& Taylor, J. R. N. (2003). Chemical and physical characterisation of grain tef [Eragrostis tef (Zucc.) Trotter] starch granule composition. Starch/Stärke, 55,304-312.

Bultosa, G., \& Taylor, J. R. N. (2004). Paste and gel properties and in vitro digestibility of tef [Eragrostis tef (Zucc.) Trotter] starch. Starch/Stärke, 56, 20-28.

Cheetham, N. W. H., \& Tao, L. (1998). Variation in crystalline type with amylose content in maize starch granules: an X-ray powder diffraction study. Carbohydrate Polymers, 36, 277-284.

Colonna, P., \& Mercier, C. (1985). Gelatinization and melting of maize and pea starches with normal and high-amylose genotypes. Phytochemistry, 24, 1667-1674.

D'Silva, T. V., Taylor, J. R. N., \& Emmambux, M. N. (2011). Enhancement of the pasting properties of teff and maize starches through wet-heat processing with added stearic acid. Journal of Cereal Science, 53, 192-197.

Ferrero, C., Martino, M. N., \& Zaritzky, N. E. (1994). Corn starch-xanthan gum interaction and its effect on the stability during storage of frozen gelatinized suspension. Starch/Stärke, 46, 300-308.

Fujita, S., Yamamoto, H., Sugimoto, Y., Morita, N., \& Yamamori, M. (1998). Thermal and crystalline properties of waxy wheat (Triticum aestivum L.) starch. Journal of Cereal Science, 27,1-5.

Godet, M. C., Bizot, H., \& Buléon, A. (1995). Crystallization of amylose-fatty acid complexes prepared with different amylose chain lengths. Carbohydrate Polymers, 27, 47-52. 
Gomes, A. M. M., da Silva, C. E. M., Ricardo, N. M. P. S., Sasaki, J. M., \& Germani, R. (2004). Impact of annealing on the physicochemical properties of unfermented cassava starch ("Polvilho Doce”). Starch/Stärke, 56,419-423.

He, H., Zhang, Y., Hong, Y., \& Gu, Z. (2015) Effects of hydrocolloids on corn starch retrogradation, Starch/Stärke, 67, 348-354.

Hizukuri, S. (1985). Relationship between the distribution of the chain length of amylopectin and the crystalline structure of starch granules. Carbohydrate Research, 141, 295-306.

Hong, Y., Wu, Y., Liu, G., \& Gu, Z. (2015). Effect of amylose on pasting and rheological properties of corn starch/xanthan blends. Starch/Stärke, 67, 98-106.

Jane, J., Chen, Y. Y., Lee, L. F., McPherson, A. E., Wong, K. S., Radosavljevic, M., \& Kasemsuwan, T. (1999). Effects of amylopectin branch chain length and amylose content on the gelatinization and pasting properties of starch. Cereal Chemistry, 76, 629-637.

Karkalas, J., Ma, S., Morrison, W. R., \& Pethrick, R. A. (1995). Some factors determining the thermal properties of amylose inclusion complexes with fatty acids. Carbohydrate Research, 268, 233-247.

Kim, H. -S., Patel, B., \& BeMiller, J. N. (2013). Effects of the amylose-amylopectin ratio on starchhydrocolloid interactions. Carbohydrate Polymers, 98, 1438- 1448.

Korus, J., Juszczak, L., Witczak, M., \& Achremowicz, B. (2004). Influence of selected hydrocolloids on triticale starch rheological properties. International Journal of Food Science and Technology, 39, 641-652.

Lodha, P., \& Netravali, A. N. (2005). Thermal and mechanical properties of environment-friendly 'green' plastics from stearic acid modified-soy protein isolate. Industrial Crops and Products, 21, 4964.

López, C. A., de Vries, A. H., \& Marrink, S. J. (2012). Amylose folding under the influence of lipids. Carbohydrate Research, 364, 1-7.

Mason, W. R. (2009). Starch use in foods. In J. N. BeMiller, \& R. L. Whistler (Eds.), Starch. Chemistry and Technology (pp. 745-795). New York: Elsevier Inc.

Muadklay, J., \& Charoenrein, S. (2008). Effects of hydrocolloids and freezing rates on freeze-thaw stability of tapioca starch gels. Food Hydrocolloids, 22, 1268-1272.

Nelles, E. M., Dewar, J., Bason, M. L., \& Taylor, J. R. N. (2000). Maize starch biphasic pasting curves. Journal of Cereal Science, 31, 287-294.

Nwokocha, L. M., Aviara, N. A., Senan, C., \& Williams, P. A. (2009). A comparative study of some properties of cassava (Manihot esculenta, Crantz) and cocoyam (Colocasia esculenta, Linn) starches. Carbohydrate Polymers, 76, 362-367.

Peroni, F. H. G., Rocha, T. S., \& Franco, C. M. L. (2006). Some structural and physicochemical characteristics of tuber and root starches. Food Science and Technology International, 12, 505-513. 
Pongsawatmanit, R., \& Srijunthongsiri, S. (2008). Influence of xanthan gum on rheological properties and freeze-thaw stability of tapioca starch. Journal of Food Engineering, 88, 137-143.

Raphaelides, S. N. (1993). Rheological studies of starch—fatty acid gels. Food Hydrocolloids, 7, 479495.

Sae-kang, V., \& Suphantharika, M. (2006). Influence of pH and xanthan gum addition on freeze-thaw stability of tapioca starch pastes. Carbohydrate Polymers, 65, 371-380.

Shi, X., \& BeMiller, J. N. (2002). Effects of food gums on viscosities of starch suspensions during pasting. Carbohydrate Polymers, 50, 7-18.

Sikora, M., Kowalski, S., \& Tomasik, P. (2008). Binary hydrocolloids from starches and xanthan gum. Food Hydrocolloids, 22, 943-952.

Srichuwong, S., Isono, N., Jiang, H., Mishima, T., \& Hisamatsu, M. (2012). Freeze-thaw stability of starches from different botanical sources: Correlation with structural features. Carbohydrate Polymers, $87,1275-1279$.

Takeda, Y., Hizukuri, S., Takeda, C., \& Suzuki, A., (1987). Structures of branched molecules of amyloses of various origins, and molar fractions of branched and unbranched molecules. Carbohydrate Research, 165, 139-145.

Tárrega, A., Durán, L., \& Costell, E. (2004). Flow behaviour of semi-solid dairy desserts. Effect of temperature. International Dairy Journal, 14, 345-353.

Temsiripong, T., Pongsawatmanit, R., Ikeda, S., \& Nishinari, K. (2005). Influence of xyloglucan on gelatinization and retrogradation of tapioca starch. Food Hydrocolloids, 19, 1054-1063.

Viturawong, Y., Achayuthakan, P., \& Suphantharika, M. (2008). Gelatinization and rheological properties of rice starch/xanthan mixtures: Effects of molecular weight of xanthan and different salts. Food Chemistry, 111, 106-114.

Weber, F. H., Clerici, M. T. P. S., Collares-Queiroz, F. P., \& Chang, Y. K. (2009). Interaction of guar and xanthan gums with starch in the gels obtained from normal, waxy and high-amylose corn starches. Starch/Stärke, 61, 28-34.

Wokadala, O. C., Ray, S. S., \& Emmambux, M. N. (2012). Occurrence of amylose-lipid complexes in teff and maize starch biphasic pastes. Carbohydrate Polymers, 90, 616-622. 